Preprint, for published version see: S. A. Coronel, J. Melguizo-Gavilanes, R. Mevel, J. E. Shepherd "Experimental and Numerical Study on Moving Hot Particle Ignition," Combustion and Flame 192, 495-506, 2018.

https://doi.org/10.1016/j.combustflame.2018.02.027

\title{
Experimental and Numerical Study on Moving Hot Particle Ignition
}

\author{
Stephanie A. Coronela,*, Josué Melguizo-Gavilanes ${ }^{\mathrm{a}}$, Rémy Mével ${ }^{\mathrm{b}, \mathrm{c}}$, Joseph E. \\ Shepherd ${ }^{\mathrm{a}}$ \\ ${ }^{a}$ Graduate Aerospace Laboratories, California Institute of Technology, Pasadena, CA 91125, \\ USA \\ ${ }^{b}$ Center for Combustion Energy, ${ }^{c}$ Department of Automotive Engineering, Tsinghua University, \\ Beijing, China
}

\begin{abstract}
Ignition thresholds for $n$-hexane-air were experimentally and numerically determined using a moving hot sphere of $6 \mathrm{~mm}$ in diameter. The novel experimental setup built for this purpose was described in detail. Two-color pyrometry was used for surface temperature measurements, and shearing interferometry flow field visualization was used to observe the onset of an ignition kernel, and subsequent flame formation and propagation. The probability of ignition was found to be $90 \%$ at a sphere surface temperature of $1224 \mathrm{~K}$. Analysis of the interferograms at the ignition threshold indicated that ignition occurs near the region of flow separation. Numerical simulations of the transient development of the 2-D axisymmetric motion and ignition were performed. Four reduced chemical mechanisms, including high and low temperature chemistry, and two diffusion models were used to determine their impact on the numerical prediction of ignition thresholds. The simulation results were unaffected by the choice of diffusion model but were found to be sensitive to the chemical kinetic mechanism used. The predicted ignition thresh-
\end{abstract}

\footnotetext{
${ }^{*}$ Corresponding author: coronel@ caltech.edu
} 
old temperatures were within $6-12 \%$ of the experimentally determined values. The numerical fields of the energy source term and a wall heat flux analysis confirmed the experimental observation that ignition occurs near the region of flow separation at the ignition threshold. Detailed analysis of the species temporal evolution at the ignition location revealed that $n$-hexane is present in small amounts, demonstrating the importance of accounting for fuel decomposition within the thermal boundary layer when developing simple chemical reaction models.

Keywords: Thermal ignition, Sphere, Interferometry, Boundary layer ignition 


\section{Introduction}

The motivations of the present study are the analysis and mitigation of potential fire and explosion hazards in industrial and transportation systems. This is a critical design issue for commercial aircraft under a range of normal operating conditions as well as anticipating equipment failures. One of the potential hazards that must be considered as part of certification is the ignition of flammable fluids (aviation kerosene, engine oil, hydraulic fluids) by hot surfaces which may be present by design (engines, hot air ducts) and can also occur due to events like

lightning strike, rotor burst or electrical system failures. At present, the analysis of hot surface ignition relies extensively on legacy guidelines that are based on empirical test methods that often have little relation to the actual hazards. The goal for the future is the development of more applicable tests and analysis methods based on the numerical simulation of thermal ignition.

The present study focuses on the canonical situation of a hot spherical particle (inert) entering a well characterized flammable atmosphere of a single component hydrocarbon fuel well mixed with air. Previous experiments on hot particle ignition include particles heated in a furnace and then injected into an explosive atmosphere, as well as stationary particles placed in an explosive atmosphere and heated via laser light. Silver [1] performed moving hot particle experiments using two different particle materials, quartz and platinum. Varying the particle material had minimal effect on the minimum ignition temperature of three different flammable mixtures: a 10\% coal-gas-air mixture (coal-gas is composed of $\mathrm{CO}_{2}$, $\mathrm{CO}, \mathrm{CH}_{4}$, and $\mathrm{H}_{2}$ ), a $3 \%$ n-pentane-air mixture, and a $20 \%$ hydrogen-air mixture. For a fixed gas mixture, the results suggest that the size and temperature of a particle were the most important factors in determining whether ignition occurs. The 
experiments performed by Silver [1] were done with particle speeds of $2-5 \mathrm{~m} / \mathrm{s}$; however, the effect of particle speed was not investigated systematically. Beyer and Markus [2] performed studies using "inert" particles suspended in an explosive atmosphere and heated via laser light. The combustible mixtures used in the experiments were $n$-pentane-air, propane-air, ethylene-air, and hydrogen-air. The studies showed that the minimum ignition temperature was weakly dependent on the equivalence ratio but was highly dependent on the fuel used. The minimum ignition temperature was also highly dependent on the particle diameter. More recently, Roth et al. [3] studied the ignition of hydrogen-air mixtures by sub-millimeter-sized particles and determined that the particle material (silicon nitride, tungsten carbide, steel, casting steel, and aluminum) had an effect on the minimum ignition temperature for a fixed mixture composition. For example, the aluminum particles had the lowest ignition thresholds $(920-1060 \mathrm{~K})$ over a wide range of diameters and the steel type 1.4034 and 1.3541 had the highest ignition thresholds $(1150-1310 \mathrm{~K})$. Additional work on stationary hot particle ignition via laser light was performed by Beyrau et al. [4, 5], Bothe et al. [6], Dubaniewicz et al. [7, 8], Dubaniewicz [9], and Homan [10].

A comparison of the experimental data of Beyer and Markus [2] and Silver [1] for a $n$-pentane-air mixture suggests that controlling for the diameter of the particle, a moving particle will have a higher minimum ignition temperature than a stationary particle. Paterson [11] saw a $300 \mathrm{~K}$ increase in the ignition threshold for a $2 \mathrm{~mm}$ diameter particle injected into a $9 \%$ coal-gas-air mixture at $10 \mathrm{~m} / \mathrm{s}$ vs. $65 \mathrm{~m} / \mathrm{s}$. In addition, Paterson [12] performed experiments, similar to Silver [1], in coal-gas-air, pentane-air, and hydrogen-air, at particle speeds of $1.2 \mathrm{~m} / \mathrm{s}$ compared to Silver's speeds of $2-5 \mathrm{~m} / \mathrm{s}$. At $1.2 \mathrm{~m} / \mathrm{s}$, the minimum ignition temperature of a 
$3 \%$ pentane-air mixture in Paterson's study was $100 \mathrm{~K}$ lower than the temperature obtained in Silver's study with higher particle velocities.

A review of previous work on experimental hot particle ignition indicates that the processes in the gas adjacent to the particle prior to and after ignition have not been examined carefully; previous experimental studies have been limited to ignition threshold measurements. Numerically, the dynamics of ignition of stoichiometric hydrogen-air mixtures by hot particles and the importance of differential diffusion effects on the prediction of ignition thresholds were topics of recent studies [13, 14]. Additionally, a simplified model was used by Mével et al. [15] to analyze the chemical kinetics of $n$-hexane-air along streamlines in the thermal boundary layer of a moving hot particle. Häber et al. [16] performed simulations of hot stationary particles suspended in a reactive mixture (similar to the setup found in Roth et al. [3]) using a one-dimensional (radial) diffusion-chemical reaction model and a 2-D OpenFOAM model. Finally, Zirwes et al. [17] studied the effect of hot particle velocity on the ignition of hydrogen-air mixtures using 2-D axisymmetric and 3-D numerical simulations.

The specific objectives of the present investigation are: 1) develop an experimental technique for creating a moving hot particle with a well characterized and controlled temperature, 2) measure ignition temperature thresholds for a particle diameter of $6 \mathrm{~mm}, 3$ ) make detailed optical observations of events in the gas near the particle surface at the ignition threshold, and 4) investigate numerically the key physical and chemical processes taking place at and near the ignition location. 


\section{Technical Approach}

\subsection{Experimental Methodology}

The ignition experiments were performed in a closed, cylindrical, stainless steel combustion vessel with a volume of approximately 22 L, shown in Fig. 1. The combustion vessel had a height of $37.5 \mathrm{~cm}$ and an inner diameter of 30.2 $\mathrm{cm}$. Two parallel flanges were used to mount $12 \mathrm{~cm}$ diameter windows for visualization. Above the vessel sat a cylindrical aluminum chamber with a volume of approximately $0.1 \mathrm{~L}$, also shown in Fig. 1. The small chamber had an inner diameter of $4 \mathrm{~cm}$ and a height of $8.9 \mathrm{~cm}$. At the bottom of the small chamber was an opening with a hollow cylinder attached to it; the cylinder extended into the inside of the combustion vessel and could be closed off with a remotely controlled electrical shutter.

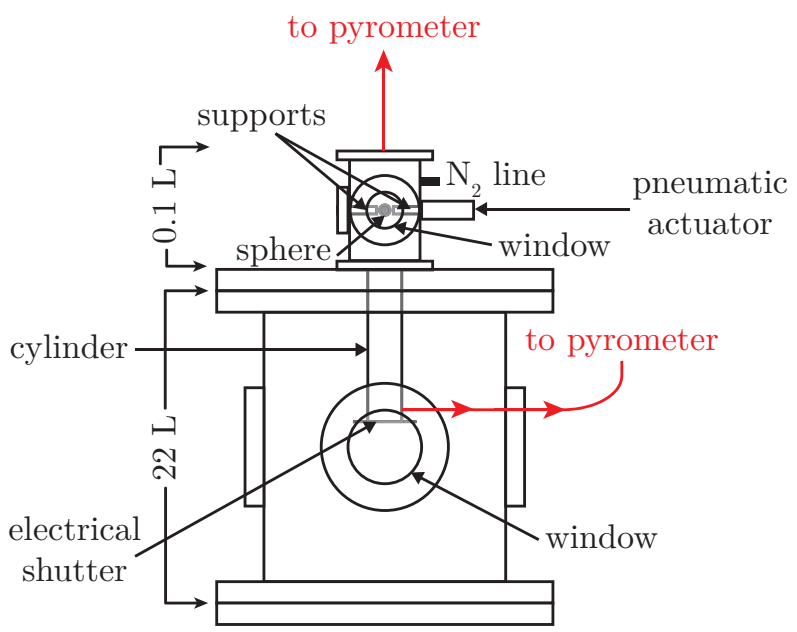

Figure 1: Combustion vessel and small chamber with components labeled; the red lines correspond to locations where temperature measurements are made using a two-color pyrometer.

The aluminum chamber was used to contain the heated spheres; it had two parallel flanges that were used to mount titanium rod supports. One support was 
actuated linearly through a double acting pneumatic actuator, the other support was fixed. The titanium supports made contact with the sphere on opposite sides, holding it in place. The other two sides of the chamber held $\mathrm{ZnSe}$ (Zinc-Selenide) windows with a field of view of approximately $1.9 \mathrm{~cm}$. A high power $\mathrm{CO}_{2}$ laser (Synrad ti80, $80 \mathrm{~W}$ ) was used to heat each sphere with illumination from both sides.

Once a sphere was in place, a remotely controlled plumbing system was used to evacuate the combustion vessel to less than $7 \mathrm{~Pa}$ and accurately fill it with the reactive mixture using the method of partial pressures. A Heise manometer with a precise digital readout measured the static pressure so the gases could be filled to within $10 \mathrm{~Pa}$ of the desired gas pressure, providing control over the mixture composition. The aluminum chamber and attached cylinder were filled with nitrogen through a port on the chamber labeled " $\mathrm{N}_{2}$ line" (see Fig. 1). The bottom end of the cylinder had an electrical shutter designed for optical systems that was closed once the chamber and cylinder were completely filled with nitrogen. This ensured that during heating, the sphere was in an inert environment and there was minimal diffusion of the nitrogen from the chamber into the reactive mixture. The bottom end of the cylinder was vertically aligned with the top of the combustion vessel windows to allow for flow visualization.

A PID (Proportional, Integral, Derivative) feedback controller used a twocolor pyrometer output to adjust the $\mathrm{CO}_{2}$ laser power, thereby allowing precise control of the sphere surface temperature during heating. An example of the power modulation during heating of a $6 \mathrm{~mm}$ diameter sphere is shown in Fig. 2. Once the desired sphere surface temperature was reached, one of the titanium supports retracted, allowing the sphere to fall. The sphere traveled through the cylinder 
(containing nitrogen) and then exited through the now open optical shutter into the combustion vessel (containing the reactive mixture) and came into the field of view of the windows. A two-color pyrometer measured the sphere surface temperature during heating (Fiber $\mathrm{A}$ in Fig. 3) and prior to entering the reactive mixture (Fiber B in Fig. 3) as indicated in Fig. 1. The two-color pyrometer used in this study, shown in Fig. 3, consisted of two $1 \mathrm{~mm}$ diameter core multimode fiber optical cables (Fiber A and Fiber B) that delivered light emitted by the radiating sphere into an optically isolated box containing optical components. The fibers delivered diverging beams of light into achromatic lenses that collimated each beam. The collimated beams were then combined using a 50/50 beamsplitter. The combined beams were incident on a dichroic mirror that transmitted and reflected light with wavelengths longer than and shorter than $1.8 \mu \mathrm{m}$, respectively. The reflected and transmitted beams were focused by plano-convex lenses onto two InGaAs (Indium, Gallium, Arsenide) photodetectors. Before each beam was incident on a photodetector, it passed through a bandpass filter centered about a specific wavelength. The reflected beam passed through a filter centered at 1.705 $\mu \mathrm{m}$ with an admittance band of $105 \mathrm{~nm}$ and the transmitted beam passed through a filter centered at $1.940 \mu \mathrm{m}$ with an admittance band of $97 \mathrm{~nm}$. Separate calibrations of the two-color pyrometer using Fiber A and Fiber B were performed using a blackbody calibration source (Process Sensors PSC-BBS1200). The mixture of interest was $n$-hexane-air; previous studies have used $n$-hexane as a suitable surrogate for kerosene $[18,19,20]$.

Four different methods were used for ignition detection. First, the pressure rise from the combustion was measured using a pressure transducer. This measurement was used to determine the peak pressure rise in the vessel. Second, the 




Figure 2: $\mathrm{CO}_{2}$ laser heating of $6 \mathrm{~mm}$ diameter sphere using a PID controller and two-color pyrometer; the set sphere surface temperature was $1280 \mathrm{~K}$ (black dashed line), the final sphere surface temperature was $1286 \mathrm{~K}$. The filtered sphere surface temperature is shown in red and the laser power is shown in blue.

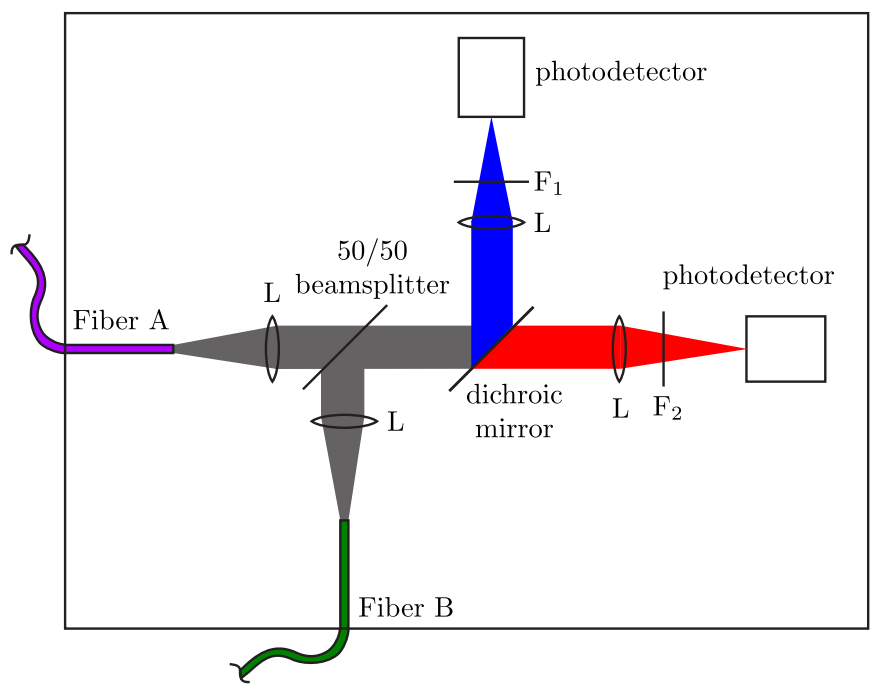

Figure 3: Two-fiber two-color pyrometer optical setup schematic; L: lens, F: bandpass filter. 
temperature rise was detected using a K-type thermocouple located inside the vessel, approximately $30 \mathrm{~mm}$ normal to the inner vessel cylindrical wall. Third, the flame emission in the infrared was observed using the two-color pyrometer photodetectors. The fourth method was a shearing interferometer, shown in Fig. 4, that used Wollaston prisms and a $532 \mathrm{~nm}$ single mode laser; details on the operation of a shearing interferometer are provided in Coronel et al. [21]. This method was used to visualize the ignition and flame propagation using a high-speed camera at 10,000 frames per second and a field of view of approximately $30 \mathrm{~mm}$.

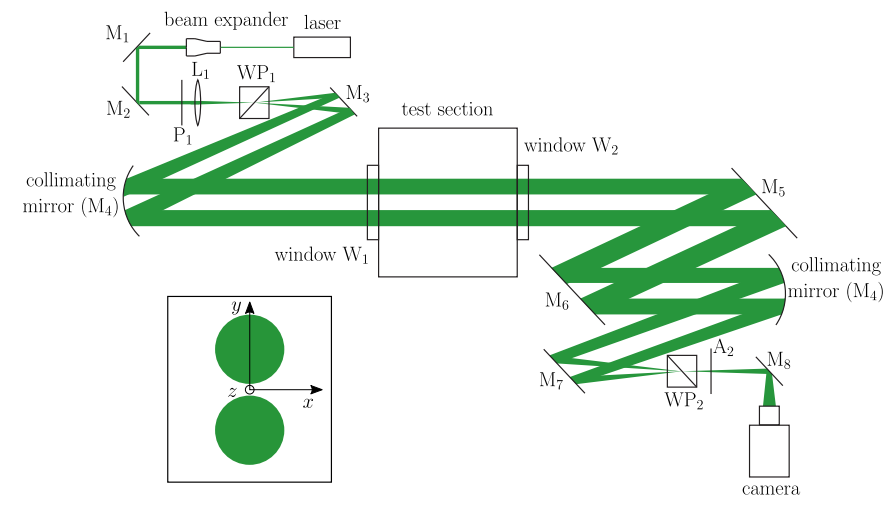

Figure 4: Shearing interferometer layout (P: polarizer, L: lens, WP: Wollaston prism, W: window, A: analyzer, M: turning mirror); a parts list for constructing the shearing interferometer can be found in the Supplementary Material.

\subsection{Computational methodology}

\subsubsection{Governing equations}

The motion, transport, and chemical reaction in the gas surrounding the sphere were modeled using the variable-density reactive Navier-Stokes equations with temperature-dependent transport properties [13]. Only the species and energy 
equations are shown below; mass and momentum conservation take their standard forms.

$$
\begin{gathered}
\partial_{t}\left(\rho Y_{i}\right)+\nabla \cdot\left(\rho \mathbf{u} Y_{i}\right)=-\nabla \cdot \mathbf{j}_{\mathbf{i}}+\dot{\omega}_{i} \\
\partial_{t}\left(\rho h_{s}\right)+\nabla \cdot\left(\rho \mathbf{u} h_{s}\right)=-\nabla \cdot \mathbf{j}_{\mathbf{q}}+\dot{q}_{\mathrm{chem}}
\end{gathered}
$$

In Eqs. 1 and 2, $\rho$ is the gas density, $Y_{i}$ is the mass fraction of species $i$, $\mathbf{u}$ is the velocity vector, $\mathbf{j}_{\mathbf{i}}=-\rho \mathcal{D}_{i, m} \nabla Y_{i}$ is the species diffusion flux, $\dot{\omega}_{i}$ represents the rate of production/consumption of species $i, h_{s}$ is the mixture sensible enthalpy, $\mathbf{j}_{\mathbf{q}}=-\kappa / c_{p}\left(\nabla h_{s}-\sum_{i=1}^{N-1} h_{s, i} \nabla Y_{i}\right)+\sum_{i=1}^{N-1} \mathbf{j}_{\mathbf{i}} h_{s, i}$ is the heat flux ( $k$ and $c_{p}$ are the temperature dependent thermal conductivity and specific heat capacity of the mixture, respectively), $\dot{q}_{\text {chem }}=-\sum_{i=1}^{N-1} \Delta h_{f, i}^{\circ} \dot{\omega}_{i}$ is the rate of conversion of chemical into thermal energy, and $\Delta h_{f, i}^{\circ}$ is the enthalpy of formation of species $i$. Gas radiation is neglected in the current model; Smith et al. [22] performed simulations using a thermal ignition model and found a difference of $2 \%$ in the ignition thresholds of hydrocarbon type fuels when accounting for heat diffusion only and heat diffusion and radiation. Two models for computing the diffusivity of each species into the mixture are used: 1) a constant but non-unity Lewis number formulation ( $\mathrm{Le} \neq 1$ ) with $\mathcal{D}_{i, m}=\kappa / \rho c_{p} \mathrm{Le}_{i}, \mathrm{Le}_{i}$ is the Lewis number of species $i$, and 2) a kinetic theory of gases based mixture averaged diffusion model $\left(\mathcal{D}_{i, j}\right)$ as detailed in Kee et al. [23].

\subsubsection{Chemical and transport models}

The chemistry was modeled using four different reduced kinetic mechanisms for $n$-hexane oxidation that were derived from the detailed mechanisms of Mével et al. [19] (531 species and 2, 628 reactions) and Blanquart [24, 25, 26] (172 species and 1,119 reactions); the mechanisms are referred to as Mével and Cal- 
techMech. The reductions were performed for $800 \mathrm{~K} \leq T \leq 1600 \mathrm{~K}, P=100$ $\mathrm{kPa}$, and $\Phi=0.9$ following the methodology described in Davidenko et al. [27] and Coronel et al. [28]. The final reduced mechanisms are labeled in this study as Mével HT (37 species and 160 reactions), Mével LT (62 species and 226 reactions), CaltechMech HT (31 species and 150 reactions) and CaltechMech LT (40 species and 162 reactions). The acronyms HT and LT stand for high temperature and low temperature, respectively, meaning that species and reactions important for the low temperature oxidation of $n$-hexane were removed from the low temperature mechanisms (LT) to create the high temperature mechanisms (HT). This was done to assess the effect of high and low temperature chemistry on the numerical prediction of ignition thresholds. Comparison of the 0-D constant pressure ignition delay time predicted with the HT and LT mechanisms against the full detailed mechanism of Mével are shown in Fig. 5.

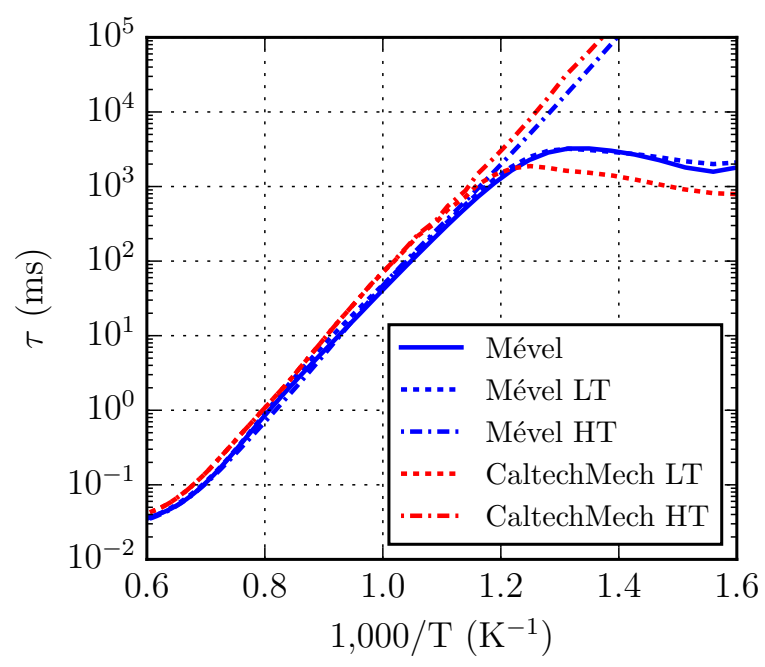

Figure 5: 0-D ignition delay time as a function of gas temperature for $n$-hexane-air at $\Phi=0.9$ and initial temperature and pressure of $300 \mathrm{~K}$ and $100 \mathrm{kPa}$, respectively. 
The Sutherland Law [29], Eucken relation [30] and JANAF polynomials [31] were used to account for the functional temperature dependence of mixture viscosity, $\mu$, thermal conductivity, and specific heat capacity, respectively. For the Le $\neq 1$ diffusion model, values of $\mathrm{Le}_{i}$ were computed with Cantera [32] using a 1-D laminar flame of $n$-hexane-air at $\Phi=0.9$. $_{i}$ values are essentially constant and usually vary in small amounts across flame fronts which justifies the validity of this approach [33]. For the $\mathcal{D}_{i, j}$ diffusion model, the transport data provided with detailed kinetic mechanisms (e.g. collision diameters, characteristic Lennard-Jones energy, etc.) were used to compute the binary diffusion coefficients, and standard mixture averaging was used to find $\mathcal{D}_{i, m}$. See Kee et al. [23] for details.

\subsubsection{Domain, initial and boundary conditions}

The simulations were carried out with initial and boundary conditions that reproduce the experimental conditions described in Section 2.1, as a result, the numerical integration was divided into two parts. First, a sphere in free fall in $\mathrm{N}_{2}$ for $0.25 \mathrm{~s}$ (fall time measured experimentally) during which a steady axisymmetric thermal boundary layer and wake develops. Second, contact with a slightly lean $(\Phi=0.9) n$-hexane-air mixture $\left(Y_{n-\mathrm{C}_{6} \mathrm{H}_{14}}=0.0561, Y_{\mathrm{O}_{2}}=0.2199\right.$, $Y_{\mathrm{N}_{2}}=0.7240$ ) for $20 \mathrm{~ms}$ (experimental observation window) or until ignition is observed and initial stages of flame propagation take place. The computational domain consisted of a vertical rectangle with a 2-D axisymmetric sphere located at $(0,0)$ with diameter $d=6 \mathrm{~mm}$. The top, bottom, and side boundaries were placed $15 d, 5 d$, and $10 d$ away from the center of the sphere, respectively. The domain was discretized using 300,000 cells with finer resolution near the sphere; a minimum cell size of $40 \mu \mathrm{m}$ ensured that the thermal/momentum boundary layers 
were properly resolved. The initial conditions were $P_{0}=100 \mathrm{kPa}, T_{0}=300 \mathrm{~K}$, and $\mathbf{u}_{0}=(0,0) \mathrm{m} / \mathrm{s}$. The sphere temperature was assumed to be spatially uniform since, experimentally, heating took place over a much longer time scale $(\sim 100 \mathrm{~s})$ than the characteristic time for heat conduction within the sphere $(\sim 1 \mathrm{~s})$. Temperature non-uniformities due to the variation in edge velocity of the momentum boundary layer around the sphere that results in a distribution of the convective heat transfer coefficient, $h$, [34] during the sphere fall were neglected. This assumption was justified since the heat transfer to the gas from the sphere occurred over a slower time scale than heat conduction within the sphere; this is explained by using a Biot number approach $\left(\mathrm{Bi}=h L_{c} / k_{s}\right)$, where $L_{c}$ is the characteristic length scale defined as $L_{c}=V / A, V$ and $A$ are the volume and surface area of the sphere, respectively, and $k_{s}$ is the thermal conductivity of the sphere material. The Biot number is the ratio of convective heat transfer from the sphere to the surrounding gas to heat conduction within a solid, a value less than 0.1 indicates that heat conduction within the sphere occurs much faster than heat transfer to the surrounding gas [35]. For the sphere material, temperature, size, and velocity considered in this study, the Biot number was 0.003. Baehr and Stephan [35] state that for a Biot number of 0.1 , the variations in temperature within a solid body are less than $2 \%$; therefore, the spatial temperature variations would be even smaller for $\mathrm{Bi}=0.003$. Finally, the global sphere surface temperature drop over the experimental observation window was also neglected. The temperature drop was estimated using engineering heat transfer relationships for the Nusselt number [36] over $20 \mathrm{~ms}$ (time at which sphere enters reactive mixture to ignition time). The temperature drop was calculated using a lumped model that took into account the convective and radiative losses from the sphere surface. For the conditions 
considered in this study, a temperature drop of $0.1 \%$ was calculated. Based on the heat transfer analysis, a uniform isothermal boundary condition was defined at the sphere surface. There was zero net flux of species to the wall, and the effects of surface heterogeneous reactions were ignored. The frame of reference was attached to the sphere, therefore, a time dependent inflow boundary condition was prescribed at the bottom of the computational domain to simulate the fall of the heated sphere. At the top, a non-reflective/pressure transmissive boundary condition was used to simulate an outflow. A schematic illustrating the simulation setup can be found in Melguizo-Gavilanes et al. [14].

The governing equations were solved using the Open source Field Operation And Manipulation (OpenFOAM) toolbox [37]. All the details about the spatial and temporal discretization can be found in Melguizo-Gavilanes et al. [13]. The implementation of the code has been validated in various ignition studies com-

prising different geometries, modes of heat transfer (e.g. forced and natural convection), and ignition timescales [13, 14, 15, 38, 39, 40].

\section{Experimental Results and Discussion}

\subsection{Overview}

Ignition tests were performed for $n$-hexane-air mixtures at an initial temperature and pressure of $298 \mathrm{~K}$ and $100 \mathrm{kPa}$, respectively. The mixture equivalence ratio was varied from 0.75 to 2.2 and alumina spheres of $d=6.0 \mathrm{~mm}$ falling at $2.4 \mathrm{~m} / \mathrm{s}$ were used as the ignition source. The two-color pyrometer calibrations were specifically made for gray-bodies, however, the emissivity of alumina varies by a small amount over the wavelength intensities measured by the pyrometer. Therefore, accounting for the variation in emissivity of the alumina spheres, the 
uncertainty of the surface temperature measurements were on average $+6 /-2 \%$. Figure 6 shows infinite fringe interferometer frames of a no-ignition (top) and an ignition (bottom) event at $t=0.0-12.5 \mathrm{~ms}$. The frame taken at $0.0 \mathrm{~ms}$ corresponds to the sphere exiting through the shutter at the bottom of the inert gas-filled cylinder and coming into contact with reactive mixture. In the ignition case (bottom) of Fig. 6, the flow around the sphere is similar to the no-ignition case flow up to $2.5 \mathrm{~ms}$, and afterwards the fringes begin to expand outwards away from the wake of the sphere, indicating that ignition has taken place. In addition, the appearance of thinner fringes at the edge of the disturbed region indicates the presence of a large density gradient corresponding to a flame. In the ignition case, after $7.5 \mathrm{~ms}$, the fringe contours in the recirculation region of the sphere show more structure than in the no-ignition case. The features in the wake suggest that there is no flame propagation directly behind the sphere, consistent with the numerical ignition simulations of Melguizo-Gavilanes et al. [14]. This indicates that at the time of ignition, the recirculation region of the sphere is composed of $\mathrm{N}_{2}$; therefore, flame propagation is not possible in the wake of the sphere. In the last ignition frame, at $12.5 \mathrm{~ms}$, the axisymmetry of the wake is evident by the two symmetric closed fringes behind the sphere, indicating that prior to ignition, the flow had a toroidal feature consistent with recirculation. In the no-ignition case the calculated Reynolds number, Re, based on the film properties of the flow, $T_{\text {film }}=\left(T_{0}+T_{\text {sphere }}\right) / 2$, is 255 and in the ignition case prior to ignition, $\operatorname{Re}=207$. The separation angle is calculated from an empirical relation described by Clift et al. [36] valid for $20<\operatorname{Re} \leq 400$, where $\theta_{\text {calc }}=180-42.5[\ln (\operatorname{Re} / 20)]^{0.483}$. $\theta_{\text {calc }}$ is $113^{\circ}$ and $116^{\circ}$ for the no-ignition and ignition cases, respectively. Flows that are steady and axisymmetric have a wake that is composed of a steady toroidal 

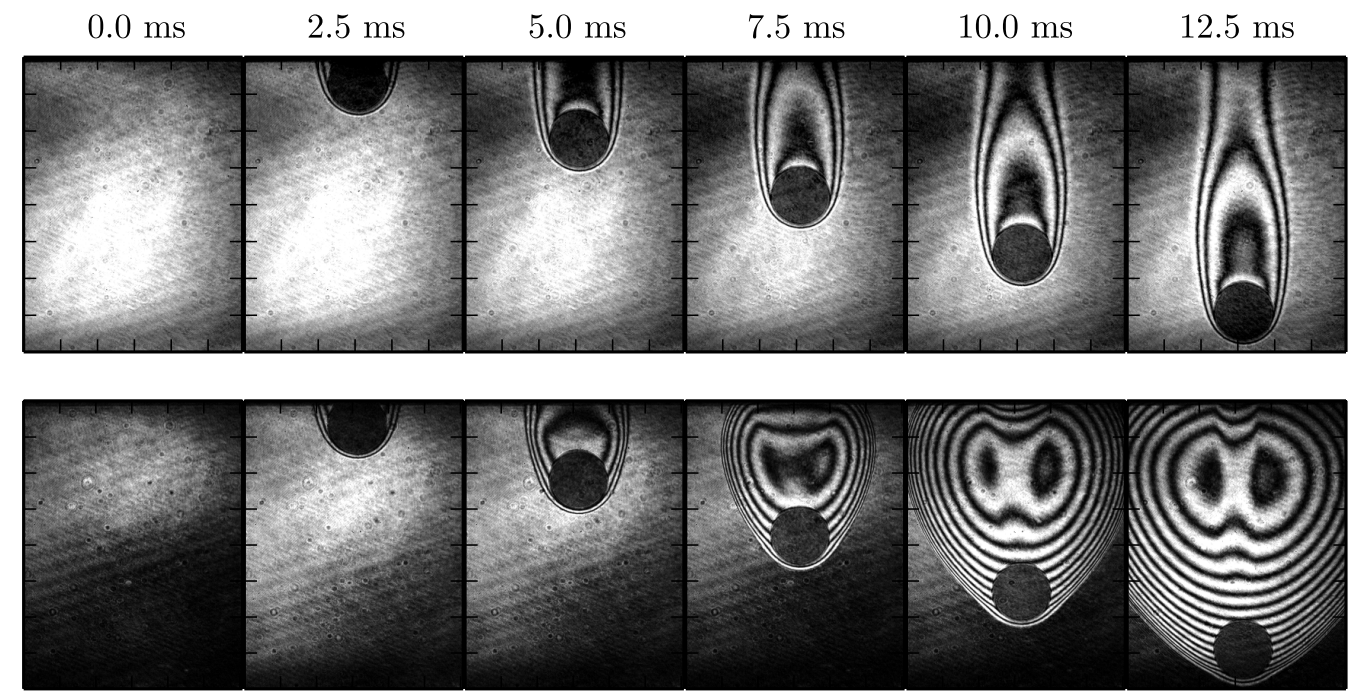

Figure 6: Infinite fringe interferometer images of no-ignition (top, shot \#17) and ignition (bottom, shot \#18) events using a $6.0 \mathrm{~mm}$ diameter sphere with surface temperatures of $1015+54 /-20$ $\mathrm{K}$ and $1185+70 /-24 \mathrm{~K}$, respectively, in $n$-hexane-air with an equivalence ratio of 0.9 and an initial temperature and pressure of $298 \mathrm{~K}$ and $100 \mathrm{kPa}$, respectively.

vortex for $20<\operatorname{Re}<210$ in uniform temperature flows, as discussed by Johnson and Patel [41]. Past $\mathrm{Re}=210$, flows become asymmetric and begin exhibiting unsteady behavior. The no-ignition case of Fig. 6 appears axisymmetric, however, it should be noted that the asymmetry could be present on a different plane.

\subsection{Effect of Mixture Composition}

The ignition and no-ignition events as a function of mixture composition are shown in Fig. 7. Previous work done by Boettcher [42] using a glow plug to ignite $n$-hexane-air mixtures indicated that the ignition threshold is independent of composition away from the flammability limits, and this is also observed in the current study. Using the ignition result ( 0 or 1$)$ as the outcome variable in a logistic regression model and the sphere surface temperature and composition 
as the independent variables yields the statistical significance of each parameter [43]. From the p-values for the regression coefficients, composition variations are not statistically significant $(\mathrm{p}$-value $=0.616)$.

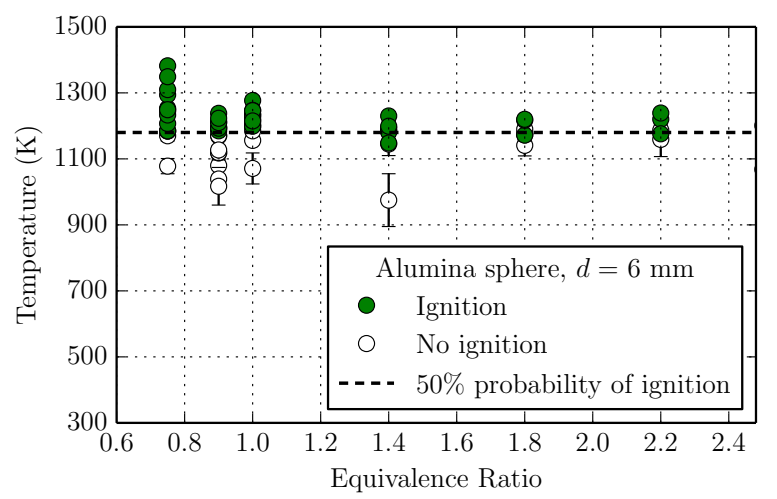

Figure 7: Hot particle ignition temperature as a function of composition in $n$-hexane-air at a nominal initial temperature and pressure of $298 \mathrm{~K}$ and $100 \mathrm{kPa}$, respectively; the closed and open markers correspond to ignition and no ignition events, respectively, and the black dashed line marks the $50 \%$ probability of ignition.

A Bayesian statistical analysis [44] of the ignition data yields a $90 \%$ probability of ignition at $1224 \mathrm{~K}$. A comparison with previous experimental work on moving hot particle ignition is not possible since the fuels used by Paterson $[11,12]$ and Silver [1] were hydrogen-air, $n$-pentane-air, and coal-gas-air, which are expected to have different ignition thresholds compared to $n$-hexane-air. However, for the 3\%-vol n-pentane-air mixture tested by Silver [1], the ignition threshold extrapolated to a sphere diameter of $6 \mathrm{~mm}$ is $1273 \mathrm{~K}$, a $4 \%$ higher threshold compared to the current results for the same sphere diameter. The similar result between $n$-pentane-air and $n$-hexane-air is consistent with shock tube ignition delay time data presented by Davidson et al. [45] who showed that the ignition delay time was weakly dependent on the carbon number for $\mathrm{C}_{5}$ to $\mathrm{C}_{9}$ normal alkanes. 
Figure 8 shows the probability distribution obtained from Bayesian analysis of the results in Fig. 7. The probability of ignition distribution is indicated by the black line, and the corresponding $95 \%$ confidence envelope is shown by the red shaded region. The ignition results are shown by the markers. A narrow overlap region of $1103-1213 \mathrm{~K}$ exists between the ignition and no ignition results; this overlap is attributed to uncertainty in the temperature measurements, variability in the incoming flow angle of the sphere, diffusion of $\mathrm{N}_{2}$ into reactive mixture, etc.

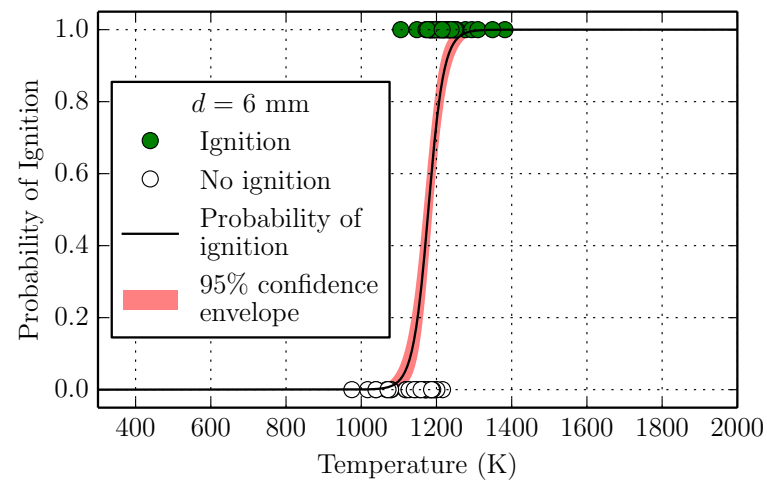

Figure 8: Probability of ignition distribution for $n$-hexane-air using a $6 \mathrm{~mm}$ diameter alumina sphere; the black line is the probability distribution, the filled and open markers are the ignition and no ignition results, respectively, and the red shaded region is the $95 \%$ confidence envelope.

Bane [46] used a measure of the relative width of the distribution to quantify the statistical variation of probability of ignition distributions obtained with spark ignition. The relative width used by Bane was in terms of the minimum ignition energy; in the context of the present study, the appropriate measure is in terms of the minimum ignition temperature,

$$
\text { Relative width }=\frac{(T)_{p=0.9}-(T)_{p=0.1}}{(T)_{p=0.5}}
$$


where $(T)_{p=q}$ is the temperature corresponding to an ignition probability $q$. The relative width calculated from $(T)_{p=0.1}=1132 \mathrm{~K},(T)_{p=0.5}=1176 \mathrm{~K}$, and $(T)_{p=0.9}=1224 \mathrm{~K}$ is 0.08 , which means the width is $8 \%$ of the mean and is much smaller than the relative widths of $23-64 \%$ obtained by Bane [46]. The results demonstrate that the statistical variation is sufficiently small that a single value for an ignition threshold is appropriate for describing these test results.

Previous studies on hot surface ignition of $n$-hexane-air mixtures yield comparable ignition thresholds. Melguizo-Gavilanes et al. [39] obtained an experimental threshold of $1275 \pm 45 \mathrm{~K}$ using a stationary glow plug measuring $9.3 \times 5.1 \mathrm{~mm}$ in height and diameter; this is approximately $4 \%$ higher than the $90 \%$ probability of ignition threshold of $1224 \mathrm{~K}$ given in Fig. 8. Using different fuels, Häber et al. [16] calculated a predicted threshold for a $6.0 \mathrm{~mm}$ diameter sphere in stoichiometric propane-air of $\sim 1200 \mathrm{~K}$ and $\sim 1100 \mathrm{~K}$ for ethylene-air. Beyrau et al. [5] obtained comparable ignition thresholds in stoichiometric butane-air of $1200 \pm 200$ $\mathrm{K}$ using smaller $(<1 \mathrm{~mm})$ silicon carbide stationary spheres with diameters of approximately 0.6 to $400 \mu \mathrm{m}$.

\subsection{Ignition Location and Time}

Determining the ignition location was possible due to the high sensitivity of the interferometer setup when placed in the infinite fringe configuration. Figure 9 shows a sequence of interferograms for ignition of a $\Phi=0.9$ mixture using a 6 $\mathrm{mm}$ diameter sphere with a surface temperature of $1276+79 /-26 \mathrm{~K}$ for $2.3 \leq$ $t \leq 11.3 \mathrm{~ms}$. To focus more closely on the region near the sphere, only half of the image is shown. There are three distinct sets of fringe patterns: the fringes are thickest in the wake of the sphere due to the toroidal vortex that produces a recirculating flow with small temperature gradients; the fringes appear unchanged 




Figure 9: Infinite fringe interferograms of ignition and flame propagation of $n$-hexane-air at $\Phi=$ 0.9 and an initial temperature and pressure of $298 \mathrm{~K}$ and $100 \mathrm{kPa}$, respectively, at $t=2.3-11.3$ ms (shot \#36); sphere surface temperature is $1276+79 /-26 \mathrm{~K}$.

up to $7.7 \mathrm{~ms}$; at this time, the fringe that is attached to the sphere close to the rear stagnation point begins to expand outwards; the expansion and generation of new fringes continues at 9.5 and $11.3 \mathrm{~ms}$, indicating the formation of a propagating flame front moving away from the sphere.

Figure 10 shows the interferograms of Fig. 9 for $7.6 \leq t \leq 8.6 \mathrm{~ms}$ using smaller time intervals bracketing the ignition event. The dark fringe attached to the sphere near the rear stagnation point begins to expand outwards between 7.6 and $7.8 \mathrm{~ms}$. This initial expansion corresponds to an ignition event taking place; the fringes expand outwards as an ignition kernel is formed which corresponds to an increase in the optical phase difference as the temperature of the gas increases. The start of flame propagation is not visibly obvious until $8.6 \mathrm{~ms}$. It is also evident from the interferograms that the initial fringe expansion corresponding to an ignition event occurs near the region of flow separation. This is determined by spatially and temporally tracking the fringes and locating the region where the fringes first begin to expand; the fringe near the calculated separation region is the 

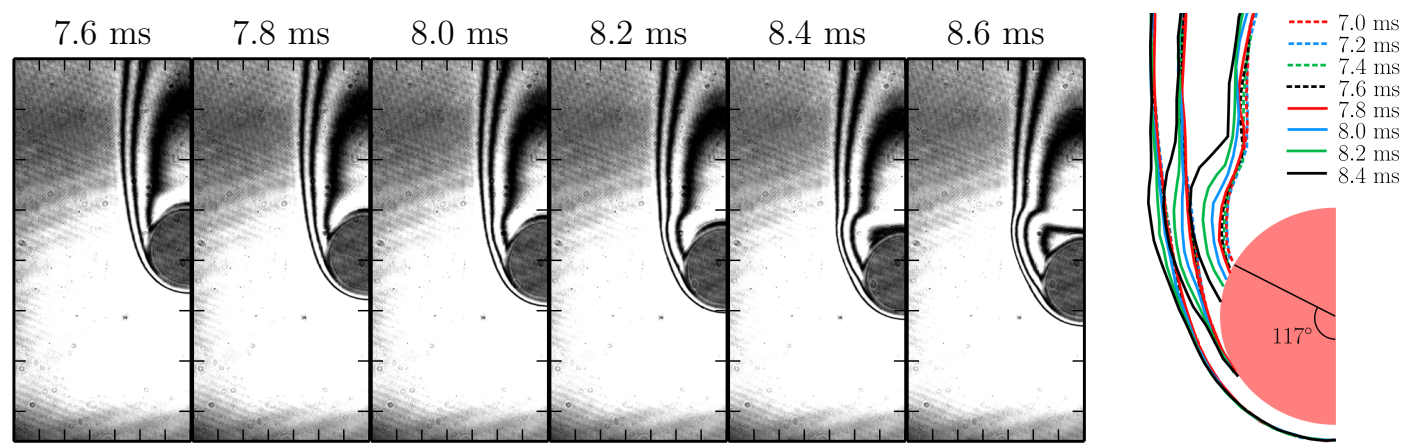

Figure 10: Infinite fringe interferograms of ignition and flame propagation of $n$-hexane-air at $\Phi=0.9$ and an initial temperature and pressure of $298 \mathrm{~K}$ and $100 \mathrm{kPa}$, respectively, at $t=7.6-8.6$ ms (shot \#36); sphere surface temperature is $1276+79 /-26 \mathrm{~K}$.

first to expand at $7.6 \leq t \leq 7.8 \mathrm{~ms}$; this is shown on the right side of Fig. 10 .

\section{Numerical Results and Discussion}

\subsection{Predicted Ignition Threshold}

Due to the weak dependence observed experimentally of the ignition threshold on the mixture composition, only one composition was simulated to determine the numerical ignition threshold. The time to ignition, $\tau_{\text {ign }}$, was determined by monitoring the maximum gas temperature in the computational domain during the duration of the simulation. Ignition was arbitrarily defined as the time at which the maximum temperature in the domain reached $T_{\text {sphere }}+150 \mathrm{~K}$. The choice of threshold temperature did not affect $\tau_{\text {ign }}$ significantly; for $T_{\text {sphere }}=1300 \mathrm{~K}$ (ignition threshold) a difference of less than $1 \%$ in $\tau_{\text {ign }}$ was obtained when choosing $T_{\text {sphere }}+100 \mathrm{~K}$ as an ignition marker instead of $T_{\text {sphere }}+150 \mathrm{~K}$. The numerical ignition thresholds were found by systematically decreasing $T_{\text {sphere }}$ from $1450 \mathrm{~K}$ in $25 \mathrm{~K}$ intervals until a self-sustained flame was no longer achieved. 



Figure 11: Ignition delay time as a function of sphere surface temperature for $n$-hexane-air at $\Phi=0.9$ and initial temperature and pressure of $300 \mathrm{~K}$ and $100 \mathrm{kPa}$, respectively.

Six sphere surface temperatures were simulated per diffusion model to determine the numerical ignition thresholds. As mentioned in Section 2.2.2, four reduced kinetic mechanisms were used, giving a total of 48 simulations to construct Fig. 11. The ignition delay times reported in this figure are measured from time to contact with the reactive mixture $(t=0 \mathrm{~ms})$ to time to ignition. Figure 11 summarizes all the numerical ignition results as a function of sphere surface temperature. The numerically predicted ignition threshold for Mével HT is $1300 \mathrm{~K}$, and $1325 \mathrm{~K}$ for Mével LT; CaltechMech yields a threshold of $1375 \mathrm{~K}$. Comparing these values to the experimental ignition threshold obtained at $90 \%$ probability of ignition $(1224 \mathrm{~K})$ results in a difference of $6 \%, 8 \%$, and $12 \%$, respectively. The ignition delay times obtained at the ignition threshold for Mével HT and LT and 
CaltechMech HT and LT are $11.63 \mathrm{~ms}$ and $9.32 \mathrm{~ms}$, and $19.46 \mathrm{~ms}$ and $19.83 \mathrm{~ms}$, respectively. The inclusion of species and reactions important for the low temperature regime (i.e. HT vs. LT) results in an increase in ignition threshold of 25 K (3\%) for the Mével mechanism; the threshold remains unchanged for CaltechMech. Notably, the use of a more sophisticated diffusion model $\left(\mathcal{D}_{i, j}\right)$ does not affect the predicted ignition thresholds regardless of the kinetic mechanism used. However, the use of the $\mathcal{D}_{i j}$ diffusion model with the Mével LT mechanism results in a faster $\tau_{\text {ign }}$ when compared to the Le $\neq 1$ model. Although the detailed mechanisms of Mével and CaltechMech have been extensively validated against experimental databases available in the literature, the 50 and $75 \mathrm{~K}$ difference $(6 \%$ and $4 \%$ increase of CaltechMech threshold from Mével HT and LT thresholds, respectively) in the ignition threshold predictions suggests that the numerical prediction of the ignition threshold is most sensitive to the choice of kinetic mechanism than diffusion model.

Figure 11 indicates that there are two limits: the minimum sphere surface temperature, $T_{\text {sphere }}$, at which ignition occurs (critical case shown by the dashed lines) and $T_{\text {sphere }}$ beyond which the reactive mixture is ignited upon contact with the sphere (supercritical case). The following section provides an analysis of the most important physical and chemical processes taking place at and near the ignition location for the two cases.

\section{2. $2 D$ Fields}

Figure 12 shows fields of fuel $\left(n-\mathrm{C}_{6} \mathrm{H}_{14}\right)$ and an important intermediate, ethylene $\left(\mathrm{C}_{2} \mathrm{H}_{4}\right)$, shortly before ignition for $T_{\text {sphere }}=1300 \mathrm{~K}(\mathrm{Re}=183$, critical case $)$ and $T_{\text {sphere }}=1500 \mathrm{~K}(\operatorname{Re}=150$, supercritical case $)$. The colorbars on the left and right correspond to the mass fractions of $n-\mathrm{C}_{6} \mathrm{H}_{14}$ and $\mathrm{C}_{2} \mathrm{H}_{4}$, respectively. In the 
critical case, the mass fraction of $n-\mathrm{C}_{6} \mathrm{H}_{14}$ is small, with values of $2.28 \times 10^{-2}$ at the front stagnation point, and decreases to zero in the flow separation region. The wake of the sphere does not contain any $n-\mathrm{C}_{6} \mathrm{H}_{14}$ as it is filled with $\mathrm{N}_{2}$. The low concentration of fuel close to the sphere is due to the decomposition of $n$ - $\mathrm{C}_{6} \mathrm{H}_{14}$ into lighter fuels such as $\mathrm{C}_{2} \mathrm{H}_{4}$. In Fig. 12 (a), the decrease in fuel is accompanied by an increase in the concentration of $\mathrm{C}_{2} \mathrm{H}_{4}$ from the front stagnation point to the separation region, eventually reaching values of $1.8 \times 10^{-2}$. The mixture that ignites is mostly composed of $\mathrm{C}_{2} \mathrm{H}_{4}$ (see curved ignition kernel in Fig. 12 (a) at $\left.\tau_{\text {ign }}-0.034 \mathrm{~ms}\right)$. This has important implications for modeling, in particular, for the development of simplified kinetic mechanisms such as one-step kinetic schemes for studying hot surface ignition. The current results suggest that fitting the kinetic parameters of a one-step model to reproduce the ignition delay times of $n$-hexane-air mixtures may not be appropriate as the mixture that actually ignites is mostly ethylene-air. These two reactive mixtures have significantly different ignition behaviors $[47,48,49,50,51,52,53]$. In the supercritical case, chemical activity is distributed along the circumference of the sphere once contact is made with the reactive mixture interface, depicted as the red-to-blue transition at $\tau_{\text {ign }}-1.56 \mathrm{~ms}$ in Fig. 12 (b). A reaction front that appears to be anchored to the sphere front stagnation point is initiated almost instantly, and expands sideways through the region where fuel-air mixture is present.

Figure 13 shows the fields of temperature and the chemical source term, $\dot{q}_{\text {chem }}$; this allows for clear visualization of the location of chemical heat release. The colorbars on the left and right correspond to the gas temperature and chemical source term, respectively. The differences between the critical and supercritical cases are evident by the size of the ignition kernel; a localized ignition kernel 

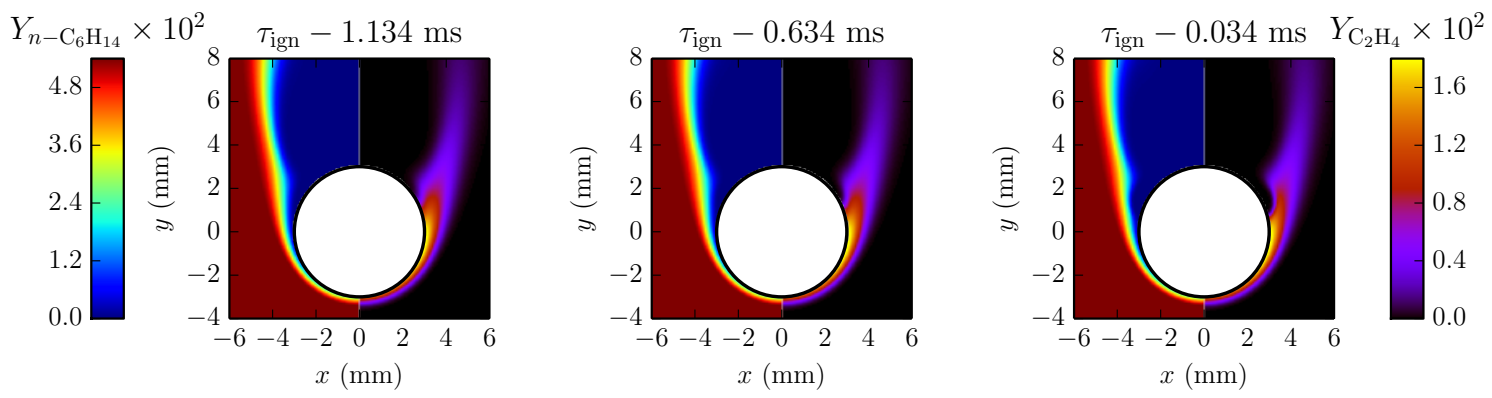

(a) $T_{\text {sphere }}=1300 \mathrm{~K}$
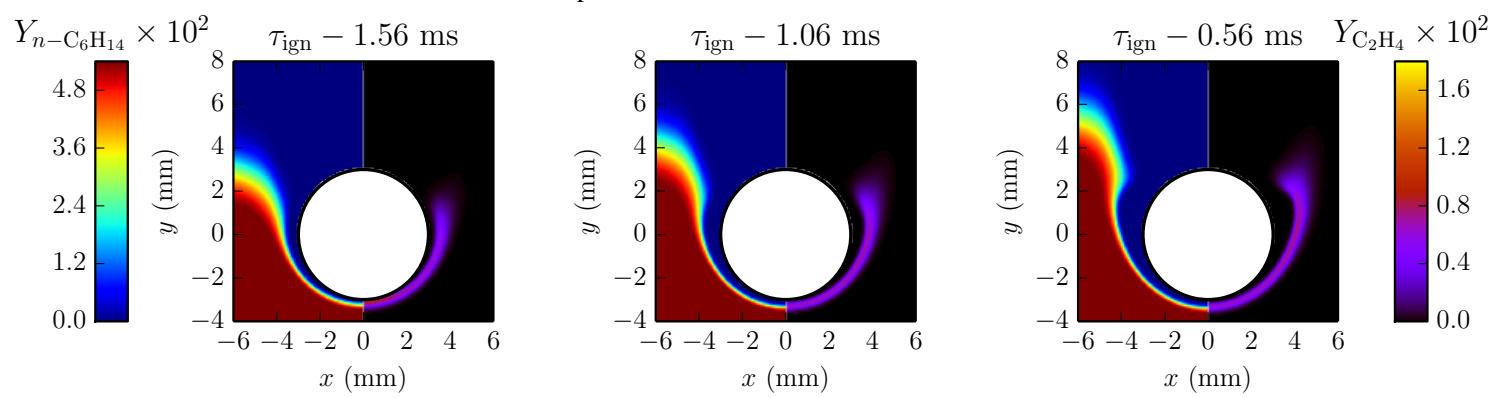

(b) $T_{\text {sphere }}=1500 \mathrm{~K}$

Figure 12: $Y_{n-\mathrm{C}_{6} \mathrm{H}_{14}}$ and $Y_{\mathrm{C}_{2} \mathrm{H}_{4}}$ fields for (a) $T_{\text {sphere }}=1300 \mathrm{~K}$ (critical case) and (b) $T_{\text {sphere }}=1500$ $\mathrm{K}$ (supercritical case) in $n$-hexane-air at $\Phi=0.9$. 

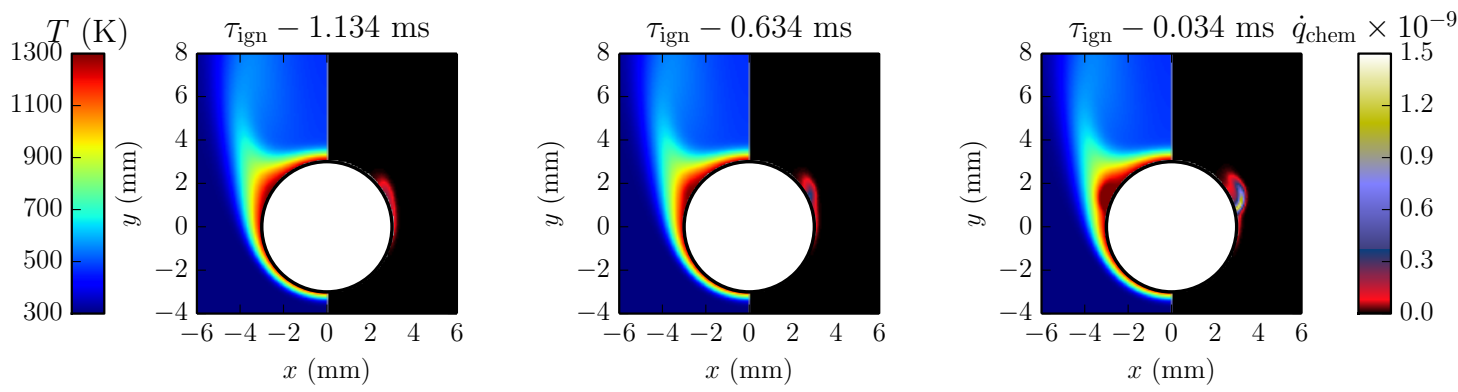

(a) $T_{\text {sphere }}=1300 \mathrm{~K}$


(b) $T_{\text {sphere }}=1500 \mathrm{~K}$

Figure 13: Temperature and chemical source term fields for (a) $T_{\text {sphere }}=1300 \mathrm{~K}$ (critical case) and (b) $T_{\text {sphere }}=1500 \mathrm{~K}$ (supercritical case) in $n$-hexane-air at $\Phi=0.9$. 
forms for $T_{\text {sphere }}=1300 \mathrm{~K}$ near the region of flow separation and a distributed reaction front along the circumference of the sphere forms for $T_{\text {sphere }}=1500 \mathrm{~K}$. The heat release zone across the flame is shown at $\tau_{\text {ign }}-0.56 \mathrm{~ms}$ in Fig. 13 (b). The flow separation region and the ignition location (red spot region in temperature field) for $T_{\text {sphere }}=1300 \mathrm{~K}$ are illustrated in Fig. 14 along with the experimental interferogram of ignition at the ignition threshold. The dashed blue line shows the location where flow first separates numerically, $\theta_{\text {sep }}$. The angle coincides with the region where a temperature increase above the sphere surface temperature is first observed (saturated red region). The dashed white line shows an overlay of the same separation angle on the experimental interferogram, in addition, the calculated separation angle of Fig. 14 is shown by the solid white line.

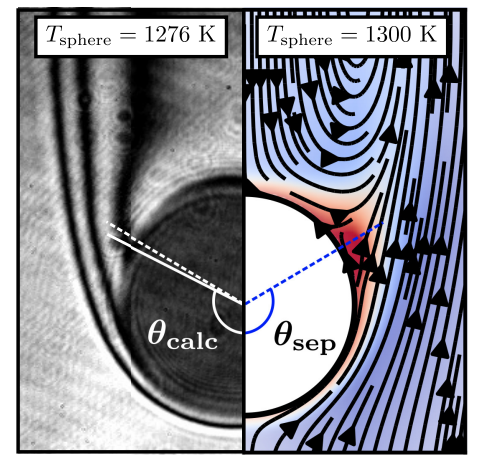

Figure 14: Overlay of numerical streamlines on temperature field (right) along with experimental interferogram (left) at ignition $(t=7.8 \mathrm{~ms})$ taken from Fig. 10.

\subsection{Wall Heat Flux and Ignition Location}

A more precise method of determining the exact ignition location is by plotting the temporal evolution of the wall heat flux along the circumference of the sphere. Initially, the heat transfer takes place from the sphere to the gas which 
results in a positive wall heat flux. However, once the gas is hot enough so that exothermic chemistry is activated, the gas reaches a higher temperature than the sphere. At this time, the heat transfer occurs from the gas to the sphere resulting in a negative wall heat flux. This transition marks the start of ignition. The region along the sphere where this transition first occurs corresponds to the ignition location. Figure 15 shows the wall heat flux as a function of normalized position along the sphere, $\theta / \pi$, with 0 and 1 corresponding to the front and rear stagnation points, respectively. The difference in the profiles between the critical and supercritical cases are evident. In the former $\left(T_{\text {sphere }}=1300 \mathrm{~K}\right)$ the negative heat flux is confined to $0.65<\theta / \pi<0.675$ for $10.5<t<10.6 \mathrm{~ms}$. For $T_{\text {sphere }}=1500 \mathrm{~K}$, there is a broader region of $0.2<\theta / \pi<0.4$ for $4.0<t<4.1 \mathrm{~ms}$ where the heat flux is negative. The values of $\theta$ at which ignition occurs based on wall heat flux analysis are $\theta=120.6^{\circ}$ (flow separation angle) and $58.5^{\circ}$ for $T_{\text {sphere }}=1300 \mathrm{~K}$ and $1500 \mathrm{~K}$, respectively. Note that choosing a single point to define the ignition location for $T_{\text {sphere }}=1500 \mathrm{~K}$ is arbitrary and was only done to enable the comparison and analysis presented in later sections.

\subsection{Energy Equation Analysis}

Ignition takes place some distance away from the hot surface as indicated by Melguizo-Gavilanes et al. $[13,14]$. This is because heat release close to the surface is immediately lost to the sphere. There exists a balance within the thermal boundary layer among the terms in the energy equation (see Eq. 2), specifically,

diffusion $=\kappa / c_{p}\left(\nabla h_{s}-\sum_{i=1}^{N-1} h_{s, i} \nabla Y_{i}\right)$, source term $=\dot{q}_{\text {chem }}=-\sum_{i=1}^{N-1} \Delta h_{f, i}^{\circ} \dot{\omega}_{i}$, and convection $=-\nabla \cdot\left(\rho \mathbf{u} h_{s}\right)$. The temperature and energy equation terms are shown as a function of wall normal distance, $\delta$, normalized by the sphere radius, $r_{\text {sphere, }}$ in Fig. 16 for the critical and subcritical cases at the ignition location. 



Figure 15: Wall heat flux for (a) $T_{\text {sphere }}=1300 \mathrm{~K}$ and (b) $T_{\text {sphere }}=1500 \mathrm{~K}$ for $n$-hexane-air at $\Phi=0.9$.

The profiles are taken at $11.6 \mathrm{~ms}\left(\tau_{\text {ign }}-0.034 \mathrm{~ms}\right)$ and $\theta=120.6^{\circ}$, and $5 \mathrm{~ms}$ $\left(\tau_{\mathrm{ign}}-0.56 \mathrm{~ms}\right)$ and $\theta=58.5^{\circ}$ for $T_{\text {sphere }}=1300 \mathrm{~K}$ and $1500 \mathrm{~K}$, respectively. The sensible enthalpy transport by species diffusion $=-\sum_{i=1}^{N-1} \mathbf{j}_{\mathbf{i}} h_{s, i}$, is also included in the figure but its contribution is negligible compared to the magnitude of the other terms. Some features stand out from Fig. 16: the thermal boundary layer, $\delta_{T}$, is almost three times thicker for $T_{\text {sphere }}=1300 \mathrm{~K}\left(\delta_{T}=1 \mathrm{~mm}\right)$ than for 1500 $\mathrm{K}\left(\delta_{T}=0.4 \mathrm{~mm}\right)$; the balance at the sphere surface is maintained between the source term and diffusion; the peak temperature occurs at $\delta / r_{\text {sphere }}=0.11$ from the sphere surface for $T_{\text {sphere }}=1300 \mathrm{~K}$ and at $\delta / r_{\text {sphere }}=0.048$ for $T_{\text {sphere }}=1500$ $\mathrm{K}$, corresponding to approximately $11-13 \%$ of their respective thermal boundary layer thicknesses.

\subsection{Temporal Evolution of Species at Ignition Location}

The temporal evolution of several species at the ignition location, shown in Fig. 17, is investigated for the critical and subcritical cases. In the critical case, 

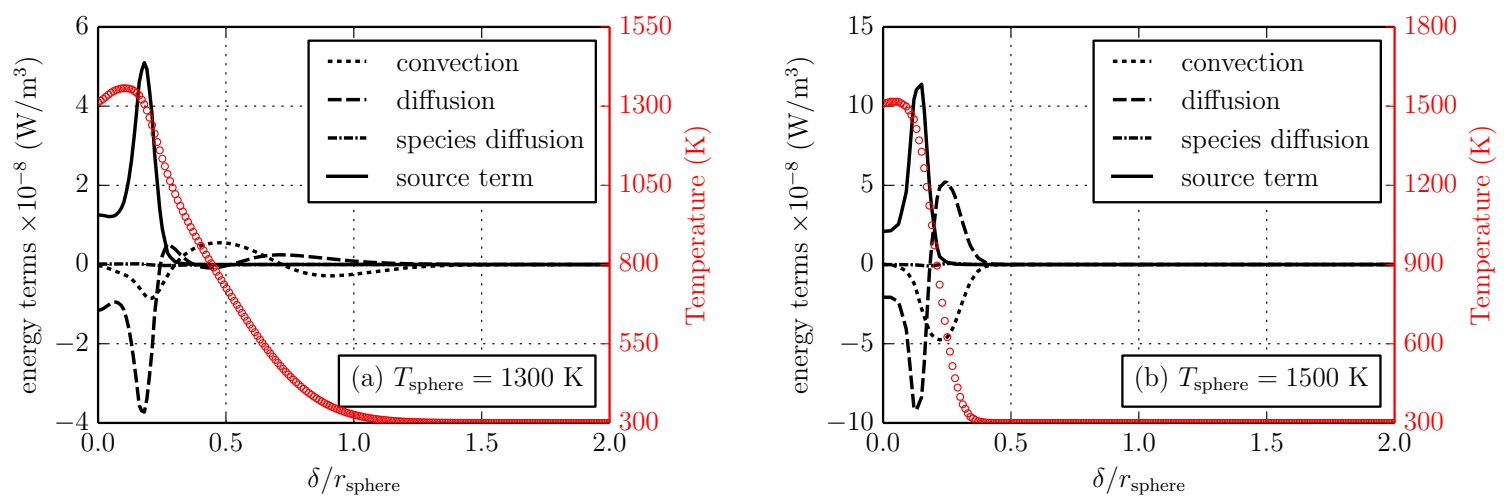

Figure 16: Contributions of each term in the energy equation and temperature as a function of normalized wall normal distance, $\delta / r_{\text {sphere }}$, at $\theta=120.6^{\circ}$ for (a) $T_{\text {sphere }}=1300 \mathrm{~K}$ and at $\theta=$ $58.5^{\circ}$ for (b) $T_{\text {sphere }}=1500 \mathrm{~K}$ for $n$-hexane-air at $\Phi=0.9$.

Fig. 17 (a), $\mathrm{O}_{2}$ and $n-\mathrm{C}_{6} \mathrm{H}_{14}$ enter the ignition location at different times due to their different diffusion velocities $\left(\mathrm{O}_{2}\right.$ being faster than $\left.n-\mathrm{C}_{6} \mathrm{H}_{14}\right)$. As mentioned in Sec. 2.1, the sphere initially falls through $\mathrm{N}_{2}$ before entering the reactive mixture, therefore, the thermal boundary layer and wake are initially filled with inert gas. Once $n-\mathrm{C}_{6} \mathrm{H}_{14}$ is transported to the ignition location it quickly decomposes into lighter compounds, mainly $\mathrm{C}_{2} \mathrm{H}_{4}$ due to the favorable $\beta$-scission process. After $5 \mathrm{~ms}$, the mass fraction of $\mathrm{C}_{2} \mathrm{H}_{4}$ becomes larger than that of $n-\mathrm{C}_{6} \mathrm{H}_{14}$. For $5<t<11 \mathrm{~ms}$, the mass fraction of $\mathrm{C}_{2} \mathrm{H}_{4}$ remains approximately constant while the mass fraction of $n-\mathrm{C}_{6} \mathrm{H}_{14}$ decreases. Ignition is signaled by the abrupt fall in the $\mathrm{C}_{2} \mathrm{H}_{4}$ mass fraction. In addition to mostly containing $\mathrm{C}_{2} \mathrm{H}_{4}$ at the ignition location, the very small drop in the mass fraction of $\mathrm{O}_{2}$ at ignition indicates that the mixture that ignites is lean. The species profiles for $T_{\text {sphere }}=1500 \mathrm{~K}$ bear some similarities with $T_{\text {sphere }}=1300 \mathrm{~K}$. Among the similarities are the arrival of fuel and oxidizer at different times due to their different diffusion velocities and 



Figure 17: Species temporal evolution at ignition location for (a) $T_{\text {sphere }}=1300 \mathrm{~K}\left(\theta=120.6^{\circ}\right.$, $0.35 \mathrm{~mm}$ away from sphere) and (b) $T_{\text {sphere }}=1500 \mathrm{~K}\left(\theta=58.5^{\circ}, 0.12 \mathrm{~mm}\right.$ away from sphere) for $n$-hexane-air at $\Phi=0.9$.

decomposition of $n$ - $\mathrm{C}_{6} \mathrm{H}_{14}$ into $\mathrm{C}_{2} \mathrm{H}_{4}$. A major difference observed between the two cases is the mass fraction of $\mathrm{H}_{2} \mathrm{O}_{2}$ surpassing that of $\mathrm{HO}_{2}$ over $2.5 \mathrm{~ms}$ for $T_{\text {sphere }}=1300 \mathrm{~K}$, whereas for $T_{\text {sphere }}=1500 \mathrm{~K}$ the mass fraction of $\mathrm{H}_{2} \mathrm{O}_{2}$ always lies below that of $\mathrm{HO}_{2}$. This indicates that for $T_{\text {sphere }}=1300 \mathrm{~K}$, intermediate temperature chemistry plays an important role in the ignition process; this is consistent with previous results obtained for $\mathrm{H}_{2}$-air mixtures by Melguizo-Gavilanes et al. [14]. Not surprisingly, the production of $\mathrm{OH}$ is favored at high temperatures reaching values of the order of $10^{-5}$ shortly after contact of the sphere with the reactive mixture, followed by a further increase during ignition. For the critical case, the production of $\mathrm{OH}$ stays below $10^{-5}$ for more than $7.5 \mathrm{~ms}$. 


\section{Conclusions}

A combined experimental and numerical study on moving hot particle ignition for $n$-hexane-air mixtures was presented. A novel experimental setup was described capable of injecting hot particles into a reactive environment. Precise heating of a particle was achieved through the use of a $\mathrm{CO}_{2}$ laser in combination with a PID controller. A shearing interferometer enabled the visualization of the gas adjacent to the particle prior to ignition, the formation of an ignition kernel, and the subsequent flame propagation. Experiments were performed using a 6 mm diameter sphere at an initial gas temperature and pressure of $298 \mathrm{~K}$ and 100 $\mathrm{kPa}$, respectively, over a wide range of mixture compositions to obtain ignition thresholds. A Bayesian approach was implemented to determine the experimental probability of ignition; the ignition threshold was well defined and had a small uncertainty $(<8 \%)$ at the $90 \%$ probability of ignition temperature of $1224 \mathrm{~K}$. The experimental interferograms of ignition at the threshold showed that ignition occurred near the region of flow separation. The experiments were modeled using the variable-density reactive Navier-Stokes equations with temperature-dependent transport properties. Four chemical mechanisms, including high and low temperature chemistry, and two diffusion models were used to determine their impact on the numerical prediction of ignition thresholds. The predicted ignition thresholds were 1300, 1325, and $1375 \mathrm{~K}$ using the Mével HT, Mével LT, and CaltechMech mechanisms, respectively. These values were unaffected by the diffusion model used, and were within $6-12 \%$ of the experimentally determined threshold. The differences obtained suggest that the numerical prediction of the ignition thresh-

old is more sensitive to the choice of kinetic mechanism than to the diffusion model used for a fixed sphere velocity and size, and fuel and mixture composi- 
tion. Heat flux, energy equation, and temporal evolution of species mass fractions analyses indicate that: 1) time to ignition in the critical case is dominated by transport of fuel-oxidizer to the thermal boundary layer originally containing $\mathrm{N}_{2}$;

2) decomposition of $n-\mathrm{C}_{6} \mathrm{H}_{14}$ to $\mathrm{C}_{2} \mathrm{H}_{4}$ occurs prior to ignition in the critical case; 3 ) in the critical case, ignition occurs near the flow separation region; 4) ignition occurs within the thermal boundary layer at a location slightly away from the sphere surface where chemical energy release can exceed losses to the wall and the gas temperature is sufficiently high to propagate chemical reactions. Analysis of the species mass fractions indicates that the use of one-step kinetic schemes for studying hot surface ignition of mid-size hydrocarbons is not appropriate since the actual mixture that ignites is composed of lighter more reactive species with significantly different ignition behaviors. Future work will focus on the development of multi-step kinetic schemes to account for decomposition of $n$-hexane into lighter hydrocarbons and experimental measurements of ignition thresholds as a function of fuel (hydrogen and ethylene) and, particle velocity, size, and material.

\section{Acknowledgments}

This work was carried out in the Explosion Dynamics Laboratory of the California Institute of Technology, and was supported by The Boeing Company through a Strategic Research and Development Relationship Agreement CT-BA-GTA-1.

\section{References}

[1] R. S. Silver, The ignition of gaseous mixtures by hot particles, Philos. Mag. 23 (156) (1937) 633-657. 
[2] M. Beyer, D. Markus, Ignition of explosive atmospheres by small hot particles: comparison of experiments and simulations, Sci. Technol. Energ. Ma. $73(1)$.

[3] D. Roth, P. Sharma, T. Haeber, R. Schiessl, H. Bockhorn, U. Maas, Ignition by mechanical sparks: ignition of hydrogen/air mixtures by submillimetersized hot particles, Combust. Sci. Technol. 186 (10-11) (2014) 1606-1617.

[4] F. Beyrau, M. A. Hadjipanayis, R. P. Lindstedt, Ignition of fuel/air mixtures by radiatively heated particles, Proc. Combust. Inst. 34 (2013) 2065-2072.

[5] F. Beyrau, M. Hadjipanayis, R. Lindstedt, Time-resolved temperature measurements for inert and reactive particles in explosive atmospheres, Proceedings of the Combustion Institute 35 (2) (2015) 2067-2074.

[6] H. Bothe, S. Schenk, S. Hawksworth, F. Carleton, F. Weinberg, The safe use of optics in potentially explosive atmospheres, in: Explosion Safety in Hazardous Areas, 1999. International Conference on (Conf. Publ. No. 469), 44-49, 1999.

[7] T. H. Dubaniewicz, K. L. Cashdollar, G. M. Green, R. F. Chaiken, Ignition of methane-air mixtures by laser heated small particles, J. Loss Prev. Process Ind. 13 (3-5) (2000) 349-359.

[8] T. H. Dubaniewicz, K. L. Cashdollar, G. M. Green, Continuous wave laser ignition thresholds of coal dust clouds, J. Laser Appl. 15 (3) (2003) 184-191.

[9] T. H. Dubaniewicz, Threshold powers and delays for igniting propane and butane-air mixtures by cw laser-heated small particles, J. Laser Appl. 18 (4) (2006) 312-319. 
[10] H. S. Homan, Minimum mass of burning aluminum particles for ignition of methane/air and propane/air mixtures, Proceedings of Eighteenth Symposium (International) on Combustion (1981) 1709-1717.

[11] S. Paterson, I. The ignition of inflammable gases by hot moving particles, Philos. Mag. 28 (186) (1939) 1-23.

[12] S. Paterson, XLII. The ignition of inflammable gases by hot moving particles, Philos. Mag. 30 (203) (1940) 437-457.

[13] J. Melguizo-Gavilanes, R. Mével, S. Coronel, J. Shepherd, Effects of differential diffusion on ignition of stoichiometric hydrogen-air by moving hot spheres, Proc. Combust. Inst. 36 (1) (2017) 1155 - 1163, ISSN 1540-7489.

[14] J. Melguizo-Gavilanes, S. Coronel, R. Mével, J. Shepherd, Dynamics of ignition of stoichiometric hydrogen-air mixtures by moving heated particles, Int. J. Hydrogen Energ. 42 (11) (2017) 7380-7392.

[15] R. Mével, U. Niedzielska, J. Melguizo-Gavilanes, S. Coronel, J. E. Shepherd, Chemical kinetics of $n$-hexane-air atmospheres in the boundary layer of a moving hot sphere, Combust. Sci. Technol. 188 (11-12) (2016) 22672283.

[16] T. Häber, T. Zirwes, D. Roth, F. Zhang, H. Bockhorn, U. Maas, Numerical simulation of the ignition of fuel/air gas mixtures around small hot particles, Z. Phys. Chem. 231 (10) (2017) 1625-1654.

[17] T. Zirwes, F. Zhang, T. Häber, D. Roth, H. Bockhorn, Direct numerical simulation of ignition by hot moving particles, in: 26th International Colloquium on the Dynamics of Explosions and Reactive Systems, 2017. 
[18] P. A. Boettcher, R. Mével, V. Thomas, J. E. Shepherd, The effect of heating rates on low temperature hexane air combustion, Fuel 96 (2012) 392-403.

[19] R. Mével, K. Chatelain, P. A. Boettcher, J. E. Shepherd, Low temperature oxidation of $n$-hexane in a flow reactor, Fuel 126 (2014) 282-293.

[20] S. A. Coronel, Thermal Ignition Using Moving Hot Particles, Ph.D. thesis, California Institute of Technology, 2016.

[21] S. A. Coronel, J. Melguizo-Gavilanes, S. Jones, J. E. Shepherd, Temperature field measurements of thermal boundary layer and wake of moving hot spheres using interferometry, Exp. Therm. Fluid Sci. 90 (2018) 76-83.

[22] T. Smith, K.-H. Byun, L.-D. Chen, Effects of radiative and conductive transfer on thermal ignition, Combustion and Flame 73 (1) (1988) 67-74.

[23] R. J. Kee, M. E. Coltrin, P. Glarborg, Chemically reacting flow: theory and practice, John Wiley \& Sons, 2005.

[24] G. Blanquart, H. Pitsch, Thermochemical properties of polycyclic aromatic hydrocarbons (PAH) from G3MP2B3 calculations, J. Phys. Chem. A 111 (28) (2007) 6510-6520.

[25] G. Blanquart, P. Pepiot-Desjardins, H. Pitsch, Chemical mechanism for high temperature combustion of engine relevant fuels with emphasis on soot precursors, Combust. Flame 156 (3) (2009) 588-607.

[26] K. Narayanaswamy, G. Blanquart, H. Pitsch, A consistent chemical mechanism for oxidation of substituted aromatic species, Combust. Flame 157 (10) (2010) 1879-1898. 
[27] D. Davidenko, R. Mével, G. Dupré, Reduced kinetic scheme for the simulation of detonation in $\mathrm{H}_{2}-\mathrm{N}_{2} \mathrm{O}$-Ar mixtures., Proc. of the European Combust. Meeting 4 (2009) 6.

[28] S. Coronel, J. Melguizo-Gavilanes, D. Davidenko, R. Mével, J. E. Shepherd, Reduction methodology for detailed kinetic mechanisms: application to $n$ hexane-air hot surface ignition, in: Asia Pacific Combustion Conference, vol. 11, 2017.

[29] W. Sutherland, LII. The viscosity of gases and molecular force, Philos. Mag. 36 (223) (1893) 507-531.

[30] B. E. Poling, J. M. Prausnitz, J. P. O'connell, et al., The properties of gases and liquids, vol. 5, Mcgraw-hill New York, 2001.

[31] A. Burcat, B. Ruscic, Third millenium ideal gas and condensed phase thermochemical database for combustion with updates from active thermochemical tables, Argonne National Laboratory Argonne, IL, 2005.

[32] D. Goodwin, H. K. Moffat, R. L. Speth, Cantera: An object-oriented software toolkit for chemical kinetics, thermodynamics, and transport processes, Caltech, Pasadena, CA .

[33] T. Poinsot, D. Veynante, Theoretical and Numerical Combustion, Edwards, 2005.

[34] S. Bhattacharyya, A. Singh, Mixed convection from an isolated spherical particle, International Journal of Heat and Mass Transfer 51 (56) (2008) 1034-1048. 
[35] H. D. Baehr, K. Stephan, Heat and Mass Transfer, Springer-Verlag Berlin Heidelberg, 2011.

[36] R. Clift, J. R. Grace, M. E. Weber, Bubbles, Drops, and Particles, Dover Publications, Inc., 2005.

[37] H. G. Weller, G. Tabor, H. Jasak, C. Fureby, A tensorial approach to computational continuum mechanics using object-oriented techniques, Comput. Phys. 12 (6) (1998) 620-631.

[38] J. Melguizo-Gavilanes, L. Boeck, R. Mével, J. Shepherd, Hot surface ignition of stoichiometric hydrogen-air mixtures, Int. J. Hydrogen Energ. 42 (11) (2016) 7393-7403.

[39] J. Melguizo-Gavilanes, A. Nové-Josserand, S. Coronel, R. Mével, J. E. Shepherd, Hot surface ignition of $n$-hexane mixtures using simplified kinetics, Combustion Science and Technology 188 (11-12) (2016) 2060-2076.

[40] J. Melguizo-Gavilanes, P. Boettcher, A. Gagliardi, V. Thomas, R. Mével, Two-dimensional numerical simulation of the transition between slow reaction and ignition, Proceedings of the 9th Joint US Sections Meeting of the Combustion Institute, 2015 .

[41] T. A. Johnson, V. C. Patel, Flow past a sphere up to a Reynolds number of 300, J. Fluid Mech. 378 (1999) 19-70.

[42] P. A. Boettcher, Thermal Ignition, Ph.D. thesis, California Institute of Technology, 2012. 
[43] R. Kabacoff, $R$ in action: data analysis and graphics with R, Manning Publications Co., Greenwich, CT, USA, 2015.

[44] A. Patil, D. Huard, C. J. Fonnesbeck, PyMC: Bayesian stochastic modeling in Python, J. Stat. Softw. 35 (4) (2010) 1-81.

[45] D. F. Davidson, S. C. Ranganath, K.-Y. Lam, M. Liaw, Z. Hong, R. K. H., Ignition delay time Mmeasurements of normal alkanes and simple oxygenates, J. Propul. Power 26 (2) (2010) 280-287.

[46] S. P. M. Bane, Spark Ignition: Experimental and Numerical Investigation With Application to Aviation Safety, Ph.D. thesis, California Institute of Technology, 2010.

[47] A. Burcat, E. Olchanski, C. Sokolinski, Kinetics of hexane combustion in a shock tube, Isr. J. Chem. 36 (3) (1996) 313-320.

[48] C. Brown, G. Thomas, Experimental studies of shock-induced ignition and transition to detonation in ethylene and propane mixtures, Combust. Flame 117 (4) (1999) 861-870.

[49] Y. Hidaka, T. Nishimori, K. Sato, Y. Henmi, R. Okuda, K. Inami, T. Higashihara, Shock-tube and modeling study of ethylene pyrolysis and oxidation, Combust. Flame 117 (4) (1999) 755-776.

[50] D. C. Horning, A study of the high temperature autoignition and thermal decomposition of hydrocarbons, Ph.D. thesis, Stanford University, 2001.

[51] D. M. Kalitan, J. M. Hall, E. L. Petersen, Ignition and oxidation of ethylene- 
oxygen-diluent mixtures with and without silane, J. Propul. Power 21 (6) (2005) 1045-1056.

[52] E. L. Petersen, Interpreting endwall and sidewall Mmeasurements in shocktube ignition studies, Combust. Sci. Technol. 181 (9) (2009) 1123-1144.

[53] T. Javed, J. Badra, M. Jaasim, E. Es-Sebbar, M. F. Labastida, S. H. Chung, H. G. Im, A. Farooq, Shock tube ignition delay data affected by localized ignition phenomena, Combust. Sci. Technol. 189 (7) (2017) 1138-1161. 


\section{Supplementary Material}

January 31, 2018

\section{Pyrometer Components}

\begin{tabular}{|c|c|c|c|}
\hline Name & Part \# & Manufacturer & Description \\
\hline Fiber A & FT1000EMT & Thorlabs & $\begin{array}{l}2 \mathrm{~m} \text { long with reinforced furcation } \\
\text { tubing }\end{array}$ \\
\hline Fiber B & FT1000EMT & Thorlabs & $2 \mathrm{~m}$ long without tubing \\
\hline Fiber A lens & LA4078 & Thorlabs & $\begin{array}{l}50 \mathrm{~mm} \text { diameter convex lens with } 75 \\
\mathrm{~mm} \mathrm{~F} / \mathrm{L}\end{array}$ \\
\hline Fiber B lens & LA4078 & Thorlabs & $\begin{array}{l}50 \mathrm{~mm} \text { diameter convex lens with } 75 \\
\mathrm{~mm} \mathrm{~F} / \mathrm{L}\end{array}$ \\
\hline 50/50 beamsplitter & BSW23 & Thorlabs & $\begin{array}{l}1 \text { inch diameter } 50: 50 \text { beamsplitter IR } \\
\text { Fused Silica }\end{array}$ \\
\hline Dichroic mirror & DMLP1800L & Thorlabs & 2 inch longpass dichroic mirror \\
\hline Red path lens & LA4078 & Thorlabs & $\begin{array}{l}50 \mathrm{~mm} \text { diameter convex lens with } 75 \\
\mathrm{~mm} \mathrm{~F} / \mathrm{L}\end{array}$ \\
\hline Blue path lens & LA4078 & Thorlabs & $\begin{array}{l}50 \mathrm{~mm} \text { diameter convex lens with } 75 \\
\mathrm{~mm} \mathrm{~F} / \mathrm{L}\end{array}$ \\
\hline F1 & ВР-1940-105-B & $\begin{array}{l}\text { Infrared Optical } \\
\text { Products }\end{array}$ & $\begin{array}{l}1 \text { inch bandpass filter centered at } 1940 \\
\mathrm{~nm} \text { with a full width half maximum of } \\
105 \mathrm{~nm}\end{array}$ \\
\hline F2 & ВР-1705-097-В & $\begin{array}{l}\text { Infrared Optical } \\
\text { Products }\end{array}$ & $\begin{array}{l}1 \text { inch bandpass filter centered at } 1705 \\
\mathrm{~nm} \text { with a full width half maximum of } \\
97 \mathrm{~nm}\end{array}$ \\
\hline Photodetectors & PDA10DT & Thorlabs & $\begin{array}{l}2 \text { InGaAs Amplified Detectors with } \\
\text { TEC, } 0.9-2.57 \mu \mathrm{m}\end{array}$ \\
\hline
\end{tabular}

Table 1: List of pyrometer components shown in Fig. 2. 


\section{Interferometer Components}

\begin{tabular}{|c|c|c|c|}
\hline Name & Part \# & Manufacturer & Description \\
\hline Laser & Sapphire SF 532 & Coherent & CW $532 \mathrm{~nm}$ single-frequency laser \\
\hline Beam expander & BE05M-A & Thorlabs & $5 \times$ Galilean optical beam expander \\
\hline $\mathrm{M}_{1}, \mathrm{M}_{2}, \mathrm{M}_{3}, \mathrm{M}_{8}$ & $43-408-533$ & Edmund Optics & $\begin{array}{l}1 \text { inch dia. enhanced aluminum, } \\
\lambda / 20 \text { Flat Fused Silica }\end{array}$ \\
\hline $\mathrm{P}_{1}, \mathrm{~A}_{2}$ & $47-215$ & Edmund Optics & $12.5 \mathrm{~mm}$ dia. linear glass polarizer \\
\hline $\mathrm{L}_{1}$ & LA4545 & Thorlabs & $\begin{array}{l}50 \mathrm{~mm} \text { dia. } 100 \mathrm{~mm} \mathrm{~F} / \mathrm{L} \mathrm{UV} \text { fused } \\
\text { silica plano-convex lens }\end{array}$ \\
\hline $\mathrm{WP}_{1}, \mathrm{WP}_{2}$ & $68-820$ & Edmund Optics & $\begin{array}{l}25.4 \mathrm{~mm} \text { dia. Quartz Wollaston } \\
\text { prism }\end{array}$ \\
\hline $\mathrm{M}_{4}$ & $32-067-533$ & Edmund Optics & $\begin{array}{l}4.25 \text { inch dia. } 34 \text { inch } F / L \text { enhanced } \\
\text { aluminum, } \lambda / 8 \text { parabolic mirror }\end{array}$ \\
\hline $\mathrm{M}_{5}, \mathrm{M}_{6}$ & $47-573-533$ & Edmund Optics & $\begin{array}{l}3 \text { inch dia. enhanced aluminum, } \\
\lambda / 20 \text { Flat Fused Silica }\end{array}$ \\
\hline $\mathrm{M}_{7}$ & $43-416-533$ & Edmund Optics & $\begin{array}{l}2 \text { inch dia. enhanced aluminum, } \\
\lambda / 20 \text { Flat Fused Silica }\end{array}$ \\
\hline camera & Phantom v711 & Vision Research & High-speed camera \\
\hline
\end{tabular}

Table 2: List of shearing interferometer components shown in Fig. 4. 